\title{
Emergência e Incerteza em jogos de Videogame
}

\section{Gustavo Audi}

Graduado em Comunicação Social na UFRJ, especialista em Mídias Digitais pela UNESA, Mestre e Doutorando no PPGCOM/UERJ.

\footnotetext{
1 "This is the story of a man named Stanley. Stanley worked for a company in a big building, where he was employee number 427. Employee number 427's job was simple. He sat at his desk in room 427 and he pushed buttons on a keyboard. Orders came to him through a monitor next to his desk, telling him what buttons to push. How long to push them, and in what order. This is what employee 427 did everyday of every month of every year".

${ }^{2}$ http://www.stanleyparable.com/
}

Resumo: O presente artigo tem como objetivo estudar a relação entre controle e liberdade criativa em jogos de videogame. Com base na teoria de sistemas complexos emergentes, pretende-se demonstrar que o jogo não é livre. Entretanto, através de técnicas de programação de inteligência artificial, mesmo evitando-se a imprevisibilidade, a incerteza sobre as ações e seus resultados é mantida. Com isso, garantem-se a tensão narrativa e participação significativa e o interesse do jogador é preservado.

Palavras-Chave: Videogame; Emergência; Incerteza.

Abstract: The present study aims to investigate the relationship between control and creative freedom in video games. Based on the theory of emergent complex systems, this article intend to demonstrate that the game is not free, however, the unpredictability is avoided by techniques of artificial intelligence programming, but the uncertainty about actions and their results is maintained. Thus, the narrative tension and meaningful participation are guaranteed and the player's interest is preserved.

Keywords: Video Games; Emergence; Uncertainty.

\section{Introdução}

Esta é a história de um homem chamado Stanley. Stanley trabalhava para uma empresa em um grande edifício, onde era o funcionário número 427. 0 trabalho do funcionário número 427 era simples. Ele sentava em sua mesa na sala 427 e apertava botões em um teclado. Ordens vinham a ele através de um monitor ao lado de sua mesa, dizendo-lhe quais botões apertar. Por quanto tempo apertá-los e em qual ordem. É isto o que o funcionário 427 fazia todos os dias de cada mês de cada ano ${ }^{1}$.

Com esta explicação, começa The Stanley Parable, desenvolvido pela Galactic Cafe. Segundo a descrição no site oficial ${ }^{2}$, é um jogo de exploração em primeira pessoa. Em um dia normal de trabalho, todos os colegas desapareceram e Stanley se vê obrigado a vasculhar o escritório para descobrir o que aconteceu. Ao longo da exploração, o narrador tenta guiar o jogador. Em uma sala, por exemplo, há duas portas; o narrador afirma que Stanley optou pela porta da esquerda.

Entretanto, há a chance de entrar na da direita. Ao fazer isto, o narrador diz que aquele não é o caminho correto. Se o jogador insistir, o narrador passa a ridicularizá-lo, dizendo: "Stanley era tão ruim em seguir direções. É incrível que ele não tenha sido demitido anos atrás. Talvez seja por isso que todo mundo foi 
3 "Stanley was so bad at following directions. It's incredible he wasn't fired years ago. Maybe this is why everyone had left. No one wanted to be around someone as bad in listening as him". embora. Ninguém queria estar perto de alguém tão ruim em ouvir como ele"3 (tradução nossa). A intenção do narrador é clara: direcionar o jogador em um percurso linear e predefinido. Por outro lado, a configuração do jogo estimula a liberdade do jogador, para que desafie o narrador e faça escolhas diferentes.

The Stanley Parable levanta questões importantes no universo dos jogos eletrônicos. Quem está no controle? O mundo do jogo é independente? A simulação permite liberdade criativa ou comportamentos imprevisíveis, tanto do jogador quanto do sistema? Estudar a liberdade criativa em jogos de videogame é considerar a capacidade do sistema de criar ou simular uma realidade inteligente e crível. E The Stanley Parable é uma alegoria desta dinâmica.

O objetivo deste trabalho é estudar como o sistema do jogo consegue simular uma existência autônoma e a liberdade do jogador no mundo ficcional. Através da configuração de sistemas complexos emergentes, o jogo é capaz de, ao mesmo tempo, exercer controle e aparentar imprevisibilidade criando incerteza sobre os eventos.

Jogos são sistemas emergentes porque permitem o surgimento de um macrocomportamento não previsto diretamente pelo desenvolvedor. São linhas de comando básicas definindo padrões e opções de ação que, combinadas pelo jogador, criam novas atividades. A complexidade está nas interações entre as variáveis do sistema que criam novas configurações não programadas anteriormente.

A imprevisibilidade do sistema, no entanto, não pode ser total. O desenvolvedor, a fim de forjar uma realidade restrita e sólida, precisa ter controle sobre o gameplay 4 e, minimamente, sobre as ações dos jogadores. Este controle evita situações impossíveis, dificuldade alta ou a completa fuga da proposta narrativa inicial.

${ }^{4}$ Não existe um consenso na tradução do termo gameplay. Normalmente, ele é traduzido como jogabilidade, entretanto, possuem características diferentes. Gameplay é mais utilizado para representar a partida realizada pelo jogador, como explicado por Sweetser (2008: 6), que afirma que o termo é composto pela forma como os jogadores usam as interações básicas para resolver problemas, atingir metas e avançar no jogo. Jogabilidade, por sua vez, relaciona-se mais à usabilidade do jogo, à análise da utilização dos seus elementos. Portanto, optou-se por não traduzir o termo gameplay.

${ }^{5}$ Não ter certeza sobre o resultado não significa evitar a Agência. Esta é a relação lógica entre uma ação e sua consequência e a possibilidade de o jogador reconhecê-la; logo, não interfere na incerteza. Evento incerto não consiste na perda de causalidade lógica.

${ }^{6}$ Optou-se por utilizar basicamente a obra de Johnson (2003) para tratar sobre Emergência devido à proximidade de conteúdo entre os autores que trabalham com este tema. As explicações e exemplos utilizados são muito próximos ou, até, iguais. Além disso, Johnson utiliza uma linguagem bastante fluida e trabalha muito bem com os exemplos - apesar de exagerar na narrativa deles em alguns momentos.
O núcleo de Inteligência Artificial é o mecanismo responsável por manter o controle, mas, simultaneamente, fornecer uma realidade lógica, aparentemente inteligente e autônoma. As diversas técnicas podem ser usadas isoladamente ou combinadas, sempre com o objetivo de contornar a lógica procedimental e simular uma dinâmica menos linear, única e imutável.

Para evitar a insatisfação e camuflar o controle exercido pelo desenvolvedor do jogo, a inteligência artificial nutre a criação de incertezas ${ }^{5}$. A sensação de não saber o que acontecerá, da dúvida sobre a eficiência de uma performance, mantém a tensão narrativa e a curiosidade do jogador. Caso isto não seja preservado e o jogador tenha certeza sobre a execução das ações e seus resultados, elevam-se as chances de o interesse desaparecer.

Apesar de consultar outros teóricos, este trabalho apoiou-se basicamente em três autores. Sobre emergência, foi utilizada a obra de Steven Johnson (2003); para a aplicação da emergência nos jogos e modelos básicos de Inteligência Artificial, escolheu-se a autora Penny Sweetser (2008); e sobre a incerteza, Greg Costikyan (2013). É importante citar também que na metodologia do estudo, além de revisão bibliográfica, utilizou-se bastante a própria prática e observação de jogos, sempre relacionando com o material teórico.

\section{Emergência}

Antes de iniciar a emergência em jogos, é preciso entender o conceito de maneira geral. Uma fonte bastante clara é o livro de Steven Johnson, Emergência ${ }^{6}$. O autor utiliza diversos exemplos a fim de explica-la a partir da definição de sistema complexo organizado. Basicamente, estes sistemas são compostos por um número moderado de variáveis inter-relacionadas por regras de interação e, assim, criam um macrocomportamento distinto (JOHNSON, 2003: 35). A complexidade está no número de elementos que compõe o sistema e na dinâmica de relacionamento entre eles, que geram imprevisibilidade sobre o resultado final. 
Luis Alberto Oliveira resume da seguinte maneira:

Podemos então definir um sistema complexo como um conjunto que possui um grande número de componentes (os agentes) interligados por um grande número de conexões e que se distribuem em agregados (os meta-agentes) hierarquizados. (...) Forma-se assim uma hierarquia estrutural de modos de organização cujos "estratos" podem vir a exibir novas propriedades e qualidades, que não são diretamente redutíveis às propriedades dos elementos dos estratos mais básicos (OLIVEIRA, 2003: 148-149).

As regras de nível mais baixo, aquelas que regem o comportamento local das variáveis do sistema, são extremamente simples, mas geram complexas relações entre elas. Emergência é exatamente este surgimento de um padrão coerente e de nível mais alto que não pode ser observado apenas focando em cada parte. Segundo Johnson, "o sistema só seria considerado verdadeiramente emergente quando todas as interações locais resultassem em algum tipo de macrocomportamento observável" (JOHNSON, 2003: 15).

Sistemas complexos emergentes seguem a lógica bottom-up, não top-down (JOHNSON, 2003: 14). Sistema top-down possui muitas linhas de comando, as regras são numerosas e bem definidas; não há inclusão de novos comportamentos, apenas a escolha entre os pré-programados. Por sua vez, sistemas bottomup possuem poucas linhas de comando (apenas o básico); ele aprende novas funcionalidades, ou aperfeiçoa as antigas, através da interação das partes entre si e das partes com o meio. Desta forma, o sistema recebe respostas sobre sua atuação-feedback - possibilitando a adaptação.

A pesquisadora Penny Sweetser (2008) simplifica sistemas complexos emergentes da seguinte forma:

Um sistema complexo é composto de muitas partes interconectadas e interdependentes. As partes podem ser simples ou complexas, mas a real complexidade vem de sua interação. De fora, o sistema parece complicado e impossível de entender. Mas, de perto, revela que é feito de muitos componentes simples, cada um seguindo um conjunto de comportamentos e interagindo com o ambiente local. (...) O macrocomportamento do sistema não é igual a simples soma de suas partes - é algo dinâmico, orgânico e vivo ${ }^{7}$ (SWEETSER, 2008: 20, tradução nossa).

A maioria dos sistemas complexos possui um conjunto de propriedades em comum: elementos, interações, formação, diversidade, ambiente e atividades (SWEETSER, 2008: 22). Como exemplo, a autora cita o cérebro humano (tabela 1).

Tabela 01 - o cérebro como sistema emergente

\begin{tabular}{|c|c|c|}
\hline Propriedade & Descrição & Cérebro \\
\hline Elementos & Componentes básicos do sistema & Neurônios \\
\hline Interações & interações entre os elementos & Sinapses \\
\hline Formação & $\begin{array}{l}\text { Como as interações e os elementos } \\
\text { são formados }\end{array}$ & Aprendizado \\
\hline Diversidade & $\begin{array}{l}\text { Grande variedade de } \\
\text { comportamentos e estados }\end{array}$ & Caminhos possiveis \\
\hline Ambiente & $\begin{array}{l}\text { O ambiente onde as interações } \\
\text { ocorrem }\end{array}$ & Corpo, mundo \\
\hline Atividades & $\begin{array}{l}\text { As atividades realizadas pelo } \\
\text { sistema }\end{array}$ & $\begin{array}{l}\text { Pensamento, comportamento, } \\
\text { controle motor }\end{array}$ \\
\hline
\end{tabular}

Fonte: Sweetser (2008) 
O uso do cérebro como exemplo é pertinente para trazer a questão da inteligência dos sistemas emergentes. Johnson relaciona a inteligência com o aprendizado. Para ele, a inteligência emergente é a habilidade de guardar e recuperar informação, reconhecer e responder a padrões de comportamento (JOHNSON, 2003). O comportamento inteligente de um sistema emergente advém das "interações locais aleatórias que conduzem à ordem global; componentes especializados criando uma inteligência não especializada; comunidades de indivíduos solucionando problemas sem que nenhum deles saiba disto" (JOHNSON, 2003: 73).

Em suma, um sistema emergente é capaz de aprender, adaptar-se e apresentar níveis de inteligência. Portanto, ser considerado inteligente não é errado. 0 problema surge ao se comparar com a inteligência e dinâmica social humanas. 0 próprio Johnson dedica um capítulo inteiro para explicar uma propriedade do ser humano que não pode ser reproduzida em outro sistema emergente.

No capítulo 6, Johnson (2003) trata sobre a habilidade do ser humano em imaginar estados mentais das pessoas; o indivíduo é capaz de construir teorias sobre outras mentes. $O$ reconhecimento de estados mentais de outras pessoas permite a autoconsciência da própria individualidade (JOHNSON, 2003). Assim, o autor associa a faculdade de "ler mentes" à autoconsciência e a considera uma propriedade emergente das redes neurais do cérebro.

Um software emergente é capaz de aprendizado bottom-up e cálculos de feedback de avaliação (JOHNSON, 2003). Contudo, basicamente, trabalhará através da criação e reconhecimento de padrões.

O programa Alexa não faz nenhuma tentativa direta de simular consciência ou inteligência humana. Em outras palavras, você não ensina o computador a ler ou apreciar o design de sites da web. O software simplesmente procura padrões em números (...). De fato, a inteligência do Alexa é a sabedoria agregada de milhares - ou milhões - de pessoas que usam o sistema. (JOHNSON, 2003: 91).

Outro exemplo dado pelo autor é o equipamento TiVo, utilizado para gravar a programação transmitida por televisão em um disco rígido. Com base nas informações salvas pelo usuário, ele é capaz de criar filtros personalizados e evitar programas indesejados, como os comerciais. TiVo "sabe" o que seu dono quer ver e, assim, de uma forma bem simples, possui uma teoria da sua mente, "mas somente sabe o que você quer ver porque você mesmo programou" (JOHNSON, 2003: 158). O software precisa de dados para formar as relações e definir padrões;

${ }^{8}$ Outro software que utiliza um sistema parecido é o programa de recomendação de produtos utilizado pela Amazon. a indicação de possíveis conteúdos é possível após esta coleta e esquematização8. Através do acúmulo de dados inseridos nos sistemas (atualizados pelo desenvolvedor ou pelos próprios usuários), eles são capazes de simular modelos mentais dos usuários.

Os seres humanos também utilizam um processo de criação de padrões, mas bem diferente. $O$ cérebro é um sistema de processamento paralelo de grande porte. Esse paralelismo permite o reconhecimento de padrões de uma maneira que um computador é incapaz, como a lembrança de um rosto ou a criação de metáforas (JOHNSON, 2003).

O cérebro humano dá sentido ao mundo através de uma complexa troca entre neurônios, o mundo exterior e os genes (JOHNSON, 2003). A relevância do material, do físico, está na essência da construção da individualidade. 0 ser humano leva anos para formar um comportamento social através de interações com outras pessoas, objetos e mundo, além de criar modelos mentais, fazer analogias e pensar por metáforas para tomar decisões e formar crenças; seria infantil acreditar que um sistema com programação básica bottom-up aberta à adaptação e evolução com base em inputs de usuários possa rapidamente 
desenvolver um comportamento genuinamente inteligente. Há a formação de uma espécie de inteligência, mas nada comparado à complexidade do cérebro humano ou às suas interações sociais.

O comportamento emergente pode ser simulado através de um sistema computadorizado. É importante reforçar que o que ocorre é uma simulação de inteligência e interação. De fato, não há (ou não deveria haver) pretensão de se criar um organismo realmente inteligente e autoconsciente. Johnson (2003) considera que a primeira geração de softwares emergentes - programas como o jogo para computador SimCity - mostravam uma qualidade orgânica e se pareciam com formas de vida ao explorar a lógica emergente bottom-up. Entretanto, possui um caráter muito mais alegórico que real. O que ocorre ao se jogar este tipo de jogo é uma ilusão de independência, um faz de conta que lembra o mundo do jogador, mas que possui diversas diferenças estruturais. $O$ trecho a seguir ilustra bem esta sensação:

Para a maioria das pessoas, a visão de sua primeira cidade digital fazendo brotar enormes bairros e favelas deprimentes é sem dúvida fascinante, como se a pesada matemática do computador digital tivesse de alguma maneira gerado uma forma de vida, algo mais orgânico e fluido, alguma coisa entre as instruções rígidas da programação e o puro acaso. (...) Como foi que Wright [criador do SimCity] criou essa extraordinária ilusão? Projetando o jogo como um sistema emergente, uma trama de células que são conectadas a outras células e que alteram seu comportamento em resposta a atitudes na rede. (JOHNSON, 2003: 65, grifo nosso).

Por não saber de onde vêm os comandos que ditam o comportamento do sistema, em função do enorme número de variáveis e cálculos inter-relacionados, só resta ao jogador acreditar que aquela simulação é independente dele, ou seja, que ela está viva. Mas isto é suficiente para o sistema ser considerado inteligente? Sim, se considerar-se o simples propósito do jogo de gerar uma experiência positiva; e não, se pensar-se como uma entidade orgânica real.

De qualquer forma, a emergência em jogos é um tema peculiar, pois acrescenta uma variável ao sistema que pode alterar qualquer tipo de configuração previamente elaborado: o jogador.

\section{Emergência em Jogos}

A emergência em jogos é lugar comum para diversos autores e designers. Salen e Zimmerman (2004: 163) afirmam que jogos geram um comportamento emergente complexo, enquanto que as estruturas formais das regras facilitam a experiência imprevisível de jogar. Para os autores (SALEN; ZIMMERMAN, 2004), a emergência surge através da interação do sistema formal do jogo e das decisões feitas pelos jogadores. O blefe no Poker é um bom exemplo, pois não faz parte das regras, mas é um comportamento que emerge no gameplay. E mais, pela descrição dada pelos autores, a presença do jogador é fundamental na criação da emergência.

${ }^{9}$ Non player character - são os outros personagens de um jogo não controlados pelo jogador.
Em jogos, portanto, é possível identificar emergência em dois estados: no sistema e no jogador. $\mathrm{O}$ sistema é emergente porque os agentes (NPCs ${ }^{9}$ e objetos) executam ou sofrem ações não previstas ou programadas diretamente. O designer não precisa definir o caminho que um personagem faz em uma rua; ele cria o mundo (física e geografia) e dota o agente da capacidade de andar, atribuindo-lhe apenas algumas diretrizes (programação bottom-up). A interação deste com o mundo e outros agentes gerará um comportamento aparentemente independente, como o trajeto escolhido. Em GTA V (ROCKSTAR NORTH, 2013), isto pode ser bem observado: na cidade de Los Santos (criada com base em Los Angeles), os NPCs circulam pelas ruas e calçadas de maneira autônoma, independente da ação do jogador. 
10 "Emergent gameplay occurs when interactions between objects in the game world or the player's actions result in a second order of consequence that was not planned, or perhaps even predicted, by the game developers, yet the game behaves in a rational and acceptable way" (SWEETSER, 2008: 3).

11 "The game allows for divergence in narrative, game flow, character interactions, or social systems" (SWEETSER, 2008: 4).
A emergência no jogador ocorre em função de ele ser mais uma variável do sistema. Suas ações impactam no mundo do jogo e geram comportamentos e configurações não definidas anteriormente. Sweetser (2008: 61) explica que o "comportamento emergente ocorre quando os jogadores usam os elementos básicos que são fornecidos pelo desenvolvedor do jogo para criar um novo gameplay (por exemplo, histórias ou estratégias)". Ou seja, basta o jogador selecionar as opções disponíveis (objetos, percursos, personagens, configurações etc.) e traçar o próprio caminho para ser considerado um comportamento emergente. Apesar da possibilidade de combinação entre estes elementos estar prevista, a combinação em si não está; a emergência, portanto, decorre disto.

Os dois estados de emergência são citados no trabalho de Penny Sweetser, ao afirmar que:

Gameplay emergente ocorre quando as interações entre objetos no mundo do jogo ou as ações do jogador resultam em uma segunda ordem de consequências que não foi planejada, ou talvez até mesmo prevista, pelos desenvolvedores do jogo, ainda assim o jogo se comporta de uma forma racional e aceitável ${ }^{10}$ (SWEETSER, 2008: 3, tradução nossa).

Sweetser (2008) separa três níveis ou ordens de emergência em jogos. Emergência de primeira ordem ocorre quando interações locais impactam um alvo imediato, mas também os elementos próximos. É uma emergência mais física, que influencia o ambiente (objetos) e torna a modelagem física e espacial mais flexível e realista.

Emergência de segunda ordem ocorre quando jogadores usam os elementos básicos do jogo para criar suas próprias estratégias e solucionar os problemas de maneiras novas. Os efeitos ainda são locais e não interferem no jogo como um todo, mas permitem maior liberdade e criatividade.

Por fim, emergência de terceira ordem refere-se ao jogo como um todo, no qual a emergência ocorre em uma escala global. Os limites do jogo são adequadamente flexíveis para permitir aos jogadores construírem caminhos próprios e únicos. "O jogo permite divergência na narrativa, fluxo de jogo, interações entre personagens ou sistemas sociais"11 (SWEETSER, 2008: 4, tradução nossa).

A construção de caminhos novos e únicos depende diretamente do número de variáveis presentes o jogo - e que permite a alta repetibilidade. Esta característica é facilmente verificada através da criação de uma narrativa emergente:

\begin{abstract}
Os elementos do enredo podem ser uma variedade de coisas, como personagens, objetos, eventos, diálogos, cutscenes, e assim por diante. O tamanho e número dos elementos vai determinar o grau de variação e emergência possíveis. (...) Quanto mais os componentes são divididos, maior o potencial que eles têm de ser reorganizados e recombinados e mais capacidade o jogo terá para narrativas emergentes. No entanto, também se torna possível e mais provável que a história criada possa não fazer sentido ou concordar com as exigências de desenvolvimento de trama interessante ou emocionante ${ }^{12}$ (SWEETSER, 2008: 320, tradução nossa).
\end{abstract}

Ou seja, a emergência está no elevado número de possibilidades predefinidas pelo sistema. Quanto maior este número, maior será a sensação de liberdade pelo jogador. Por outro lado, para isto acontecer, o nível de controle da narrativa pelo desenvolvedor tem de diminuir. O equilíbrio dependerá do gênero e objetivo do jogo - um RPG precisa de maior número de opções; já um action/adventure, não, pois focará nas habilidades físicas. requirements for interesting or exciting plot development" (SWEETSER, 2008, 320). 
Apesar de a emergência depender de alta liberdade de ação e imprevisibilidade, o controle é fundamental para manter a coerência narrativa e, inclusive, a própria experiência emergente.

\section{Controle}

Mesmo nos jogos de terceira ordem de emergência - em que, teoricamente, haveria liberdade para se criar-, o sistema ainda possui controle sobre o gameplay. As opções e suas consequências são pré-programadas. Por mais paradoxal que pareça, a imprevisibilidade da emergência é prevista pelo desenvolvedor do jogo a fim de permitir um gameplay mais fluido.

Primeiramente, jogos precisam de regras, assim como os sistemas emergentes. Segundo Johnson:

Os sistemas emergentes também são sistemas regidos por regras: sua capacidade de aprendizado, crescimento e experimentação deriva de sua adesão às regras de nível baixo. (...) Os comportamentos emergentes, assim como os jogos, vivem dentro de limites definidos pelas regras, mas também usam esse espaço para criar algo maior do que a soma das partes (JOHNSON, 2003: 135).

A presença de regras está na definição de jogo de diversos autores, como Huizinga (2008), Frasca (2007), Juul (2003), Aarseth (1997) e Salen e Zimmerman (2004). De maneira geral, as regras são possibilidades de ação, a mecânica possível e os objetivos (obrigatórios, opcionais ou inexistentes) - ou seja, em relação à ação do jogador, é o que pode ser feito, como será feito e com que finalidade. Para Salen e Zimmerman (2004), caracterizam-se como a organização estrutural do sistema, definindo o que o jogador pode ou não fazer e a relação entre a entrada e saída de dados. Na maioria das vezes, são arbitrárias, pois criam condições artificiais para o mundo do jogo; como em L.A. Noir (ROCKSTAR NORTH, 2011), em que somente as portas com maçaneta dourada podem ser abertas.

As regras controlam o sistema do jogo criando limitações na gama de possibilidades de eventos a fim de tornar o mundo do jogo uma realidade possível e viabilizar a experiência lúdica. Também diminuem a autonomia do sistema, valorizando a participação do jogador, e direcionam-no a eventos, como superar um obstáculo, progredir na narrativa, passar de fase, etc. Por exemplo, para o jogador abrir uma porta e passar para a aventura seguinte, ele precisa de uma chave mágica (regra 1). A chave só pode ser obtida derrotando um monstro (regra 2) e a magia só pode ser adquirida conversando com um mago (regra 3). Assim, o jogador é obrigado a explorar o ambiente em dois locais (monstro e mago) e ainda saber mais sobre a história ao conversar com o mago.

Mesmo os sistemas emergentes não são anarquias totais, pois obedecem a regras pré-definidas; mas essas regras só governam os micromotivos (JOHNSON, 2003: 125). Os micromotivos são os eventos de emergência local. Contudo, o comportamento macro, segundo Johnson, não é controlado por ninguém. "Tudo o que se pode fazer", afirma, "é estabelecer as condições que supostamente vão tornar aquele comportamento possível" (JOHNSON, 2003: 125).

Nas palavras de Johnson (2003: 126): "desde o início, a arte de programar tratou de sistemas de controle e da melhor maneira de conduzi-los." Obviamente, com a entrada de softwares emergentes, a necessidade de se programar tudo que o sistema precisa saber diminuiu enormemente. Este tipo de programação permite autonomia. Por outro lado, o leque de possibilidades de um mecanismo aberto pode interferir na própria experiência do jogo, já que "um jogo em que qualquer coisa pode acontecer por definição não é um jogo" (JOHNSON, 2003: 137). As regras, por natureza, restringem o mundo. 
${ }^{13}$ Lembrando que isso não significa, automaticamente, inteligência.
14 “(...) needs to exhibit human error and personality, be able to employ different difficulty levels, and make the human feel adequately challenged" (SCHWAB, 2009: 29).

15 "Player enjoyment is the single most important goal for computer games. If players do not enjoy a game, they will not play the game. Enjoyment is a far deeper concept than "fun", which infers light and fleeting entertainment. Enjoyment pertains to a more basal pleasure that can only be achieved by being completely absorbed by something, with a sense of accomplishment and alteration at its completion" (SWEETSER, 2008: 64).
Em suma, o lado negativo da utilização de sistemas emergentes totais (sem restrições) em jogos inclui a imprevisibilidade no processamento evolutivo e a forte autonomia do mundo do jogo. Como citado por Johnson (2003), os poderes da seleção natural são imprevisíveis demais para o universo controlado por regras dos videogames. Sem um freio apropriado, a evolução formará um sistema sem limites de adaptação, totalmente autônomo, instituindo soluções independentes do planejamento do programador $^{13}$ - algo que inviabiliza a narrativa com base em uma história.

Além disso, em termos práticos, o alto processamento elevará enormemente a dificuldade de combater os NPCs; em um FPS, os inimigos estarão em um nível sempre acima do jogador, pois evoluirão ao longo da partida, impossibilitado qualquer tentativa de sucesso. Segundo Zimmerman (apud JOHNSON, 2003: 138139), "o desafio é o seguinte: quanto mais autônomo é o sistema, mais autônomas são as criaturas e mais irrelevante é o jogador".

Como controlar, mas ao mesmo tempo simular um organismo autônomo? Como limitar o poder de processamento lógico do sistema, mas ao mesmo tempo fazêlo parecer inteligente? São questões importantes no design de jogos e apenas respondidas pelo núcleo de programação da inteligência artificial.

\section{Inteligência Artificial}

É importante destacar a diferença entre a inteligência artificial acadêmica e a utilizada nos design de jogos. Basicamente, os propósitos são outros, o que impacta no processo e sua avaliação. No caso da Inteligência Artificial (IA) acadêmica, o objetivo é entender como funciona a inteligência humana e reproduzi-la. Segundo Regis (2012: 114-115) é possível separar os estudos em duas abordagens principais:

a) Inteligência artificial clássica GOFAI (good old fashioned artificial intelligence) - desenvolve tarefas que parecem requerer inteligência lógico-matemática; o programador fornece as instruções para a realização da tarefa através de processamento top-down.

b) Conexionismo - leva em consideração os mecanismos sensório-motores evoluídos dos seres humanos; modelização por computador de sistemas nervosos animais através de processamento bottom-up.

O estudo de IA em jogos eletrônicos dedica-se à simulação e convencimento do jogador a fim de garantir uma experiência satisfatória. Sua necessidade surgiu com a criação de jogos single player. Para o gamedesigner Brian Schwab, inteligência artificial em jogos (Game Al) precisa ser esperta e divertida porque é primeiramente uma forma de entretenimento, assim "precisa exibir personalidade e erros humanos, ser capaz de empregar níveis de dificuldade diferentes e fazer o jogador se sentir adequadamente desafiado14" (SCHWAB, 2009: 29, tradução nossa). E, segundo Sweetser,

a satisfação do jogador é o objetivo mais importante para jogos de computador. Se os jogadores não gostam de um jogo, eles não vão jogá-lo. Satisfação é um conceito mais profundo que "divertimento", que infere entretenimento leve e efêmero. Satisfação pertence a um prazer mais básico que só pode ser alcançado ao ser completamente absorvido por algo, com um sentimento de realização e alteração em sua conclusão ${ }^{15}$ (SWEETSER, 2008: 64, tradução nossa).

O Game Al utiliza conceitos da IA clássica, conexionismo e darwinismo para criar sua programação. Entretanto, não há aprofundamento real na tentativa de criação de sistemas realmente autônomos, autoconscientes e inteligentes - o foco é a simulação e convencimento do jogador a fim de garantir o divertimento. 
Em jogos, a maneira como a emergência será utilizada (ordens, local ou global etc.) dependerá do gênero do jogo e do nível de controle criativo requerido (SWEETSER, 2008).

16 "Role-playing games could include emergence in the form of characters that have general rules for behavior, conversation and goals, rather than specifically scripted dialogue. Firstperson shooter games could include emergent objects, enemies, and buildings. Strategy games can include emergent environmental effects, as well as active and reactive buildings, units, and terrain" (SWEETSER, 2008: 112).

${ }^{17}$ Amaro, Maia e Perani (2012: 257-258) definem algoritmos como os "comandos lógicos que descrevem princípios de ação, métodos e resultados esperados possibilitando o exercício de atividades predeterminadas pelos programadores. (...) série limitada de tarefas realizadas pelo programa, cujo objetivo é executar uma determinada tarefa." De maneira similar, Oliveira (2003: 171) afirma que algoritmo é "uma sequência de repetições 'cegas' de um procedimento local (um comando do tipo "se p, então q"), cuja reiteração e acumulação acabam por produzir um efeito global qualitativamente diferente, aparentando 'intencionalidade' ou 'finalidade."

${ }^{18}$ Dos autores consultados, optouse pela nomenclatura e conjunto de técnicas utilizadas por Penny Sweetser (2008: 117-168). As outras fontes foram Schwab (2009), Kishimoto (2004) e Karlsson (2005); além de tutoriais de sites especializados em design de jogos e IA

${ }^{19} \mathrm{O}$ campo da inteligência artificial em jogos é totalmente relacionado à linguagem de programação. Como não é foco deste trabalho, optou-se por não detalhar a mecânica de cada técnica; o objetivo aqui é trazer apenas as diversas tecnologias de simulação de inteligência, sem entrar em detalhes configurativos ou linhas de comando.

20 "Game developers have been reluctant to use in-game learning due to the possibility of unexpected and undesirable behavior and have preferred to train their networks during development and lock the settings before shipping" (SWEETSER, 2008: 141-142).
RPGs podem incluir emergência na forma de personagens que possuem regras gerais de comportamento, conversação e objetivos, ao invés de especificamente diálogos em script. FPSs podem incluir objetos emergentes, inimigos e edifícios. Jogos de estratégia podem incluir efeitos ambientais emergentes, bem como edifícios ativos e reativos, unidades e terreno ${ }^{16}$ (SWEETSER, 2008: 112, tradução nossa).

Há diversas técnicas que facilitam tanto o comportamento emergente quanto a programação simples e linear, desde sistemas complexos a algoritmos se-então ${ }^{17}$. Cada autor enumera aquelas que considera mais importante. Muitas vezes, a técnica é a mesma, ou possui pequenas diferenças conceituais, mas com nomes distintos $^{18}$. Uma unanimidade é a criação da aparência ou ilusão de realidade ou inteligência - em muitos jogos, a IA se resume ao que os jogadores conseguem perceber e se eles estão convencidos que o jogo se comporta racionalmente.

A partir dos modelos existentes, é possível separá-los em três grupos não excludentes: emergentes, não-determinísticos e determinísticos ${ }^{19}$.

Os modelos determinísticos são finite state machines (FSMs - máquinas de estado finito) e scripting. Caracterizam-se por uma linguagem top-down e linear, prevendo todas as opções e configurações. Jogos que utilizam FSM são Doom e Age of Empires. Um FPS pode usar o scripting para criar a inteligência de um monstro ou, em um RPG, para definir como os feitiços funcionam.

Os modelos não-determinísticos são formados pela lógica fuzzy e a fuzzy state machines (FuSM). Comparadas às técnicas lineares, apresentam maior flexibilidade e variação em função do uso de diferentes graus para os estados. As FuSM podem ser usadas em um RPG ou FPS para contabilizar a energia ou HP dos NPCs. Jogos que usam estas técnicas incluem Civilization: Call to Power e The Sims.

Nos modelos de IA não emergentes, não há possibilidade de aprendizado, apenas um conjunto (complexo ou não) de possibilidades comportamentais. Os modelos emergentes são representados por decision trees, neural networks, flocking, evolutionary algorithms e cellular automata. Nestes modelos, a máquina é capaz de reconhecer padrões, aprender com eventos passados e adaptar comportamentos. Devido a este caráter emergente, eventos novos não programados podem ser criados. Decision trees (árvores de decisão) é uma técnica usada para prever e classificar tomando a forma de uma estrutura em árvore. Neural networks (redes neurais) são técnicas para aprendizado e tomada de decisão na qual o conhecimento é adquirido a partir do ambiente através de um processo de aprendizado, e a força da conexão em rede é usada para armazenar o conhecimento adquirido. A série de jogos SimCity utiliza a técnica de cellular automata para modelar o estado dinâmico das cidades simuladas.

Segundo Sweetser,

Desenvolvedores de jogos têm sido relutantes em usar a aprendizagem dentro do jogo devido à possibilidade de comportamento inesperado e indesejável e têm preferido treinar suas redes durante o desenvolvimento e bloquear as configurações antes de lançar ${ }^{20}$ (SWEETSER, 2008: 141-142, tradução nossa).

Além da imprevisibilidade gerada pela emergência, dependendo do modelo de IA escolhido, a necessidade de processamento variará bastante - quanto mais complexo o sistema, maior o poder de processamento exigido. Assim, para se 
criar, por exemplo, a lógica de movimentação de uma horda de monstros através da técnica de flocking, é necessário um tempo considerável de processamento exclusivo; com isso, o jogo congelará muito tempo na tela de "loading" até todas as linhas de comando serem criadas e representadas. $O$ ideal, portanto, é que o processamento emergente seja feito ainda no desenvolvimento do jogo e não no gameplay - e é o que muitos designers fazem.

A IA possui um papel fundamental no desenvolvimento de jogos, pois, através da simulação de inteligência e autonomia do mundo do jogo, ela cria uma dinâmica teoricamente imprevisível. A imprevisibilidade, a princípio, seria um elemento fundamental para o gameplay aberto e, assim, tenso e satisfatório. Entretanto, como visto anteriormente, o controle sobre o estado do jogo é fundamental para a experiência positiva. Neste caso, por um lado, saber as possíveis ações desfaz a imprevisibilidade, mas, por outro, não interfere na incerteza sobre o gameplay e os resultados.

\section{Incerteza em Jogos}

Greg Costikyan (2013) dedica uma obra inteira para tratar da incerteza. Para o autor, a incerteza enfrentada na vida cotidiana é transformada culturalmente através de construções elaboradas de maneira ficcional e não ameaçadora - o jogo. O encanto dos jogos está exatamente no interesse e luta para dominar a incerteza. Sem ela, perde-se a inventividade e o prazer de jogar (COSTIKYAN, 2013)

Segundo Costikyan (2013), o que ele chama de incerteza, o antropólogo cultural Thomas Malaby chama de "possibilidade", e está atrelada a lógica de "se A, então B". Malaby alega que a razão principal para jogos serem convincentes é porque criam um contexto restritivo que apela para a natureza fundamental do indivíduo de explorar a incerteza para combater a imprevisibilidade.

A imprevisibilidade ligada a incerteza também é citada por Sweetser (2008). Segundo a autora, a incerteza é uma propriedade importante dos sistemas emergentes, que dá origem a um comportamento novo e inesperado - algo que pode ser considerado perigoso para os desenvolvedores de jogos, pois se perderia o controle sobre o gameplay.

21 "When human players are introduced into an emergent system, they have the ability to use the system in ways it was not meant to be used, change things in the game that the developer had not expected, and play the game in ways that could not be foreseen. Furthermore, human players seem to have a perverse drive to intentionally push the game to its limits, exploit its weaknesses, and to make it break. Consequently, game developers' fears of using emergent systems are justified" (SWEETSER, 2008: 111).
Quando jogadores humanos são introduzidos em um sistema emergente, eles têm a capacidade de usar o sistema de forma que não foi feito para ser usado, mudar coisas no jogo que o desenvolvedor não esperava e jogar de uma forma que não poderia ser prevista. Além disso, os jogadores humanos parecem ter um ímpeto perverso para forçar intencionalmente os limites do jogo, explorar seus pontos fracos e fazê-lo falhar. Consequentemente, os temores dos desenvolvedores em usar sistemas emergentes são justificados ${ }^{21}$ (SWEETSER, 2008: 111, tradução nossa).

O que ocorre é uma confusão sobre o uso do termo imprevisibilidade. Sistemas emergentes na natureza são imprevisíveis, contudo, em jogos, esta característica não é desejada. Neste ponto, é importante esclarecer o uso dos termos especificamente pensando em jogos eletrônicos.

Imprevisibilidade é a qualidade do que não é previsível, que não pode ser visível com antecipação; ou seja, é a impossibilidade de saber algo com antecedência. É caracterizada por uma inviabilidade de se saber o que vai acontecer, entretanto, não impede a suposição. Por exemplo, a frase "o tempo está imprevisível" significa que não se consegue prever o clima. Contudo, as possibilidades existem e são limitadas, apesar de serem numerosas: chuva, sol, nublado, frio, quente, neve, granizo etc. Assim, é viável conjecturar sobre o que pode acontecer. Neste caso, define-se algo, mas não se tem certeza disso. É possível prever chuva, apesar de a previsão ser incerta. Desta forma, a imprevisibilidade impede o conhecimento do que vai 
22 "Uncertainty is a central feature of every game. (...) Uncertainty about the outcome of a game is a necessary ingredient in giving a game a feeling of purpose" (SALEN; ZIMMERMAN, 2004: 174).

\footnotetext{
${ }^{23}$ A narrativa pode ser a história sendo contada, com personagens, enredo, plot points, clímax, ou simplesmente a sequência de eventos de um jogo - contanto que possa ser, posteriormente, visualizada como uma cadeia sequencial causal.
}

acontecer, mas não do que pode acontecer. E esta diferença é fundamental no jogo, que não pode ser totalmente imprevisível, pois é limitado por regras pré-definidas. As regras controlam o sistema do jogo criando limitações na gama de possibilidades de eventos a fim de tornar o mundo do jogo uma realidade possível e viabilizar a experiência lúdica. Em jogos, é preciso ter em mente que imprevisibilidade não significa necessariamente desconhecimento completo daquilo que está por vir. Em função disso, o uso do termo incerteza é, muitas vezes, preferível.

A visão de Salen e Zimmerman (2004) sobre a incerteza é bem resumida, apesar de deixarem a importância do tema bem clara. Para eles, a "incerteza é uma característica central de qualquer jogo. (...) Incerteza sobre o resultado do jogo é um ingrediente necessário para dar uma sensação de propósito"22 (SALEN; ZIMMERMAN, 2004: 174, tradução nossa). Se um jogo não possuir incerteza sobre os resultados, tanto em um nível local quanto global, as escolhas do jogador não possuirão sentido - gameplay significativo surge a partir de escolhas significativas.

Como a incerteza ou imprevisibilidade no design de jogos são estados minimamente controlados pela programação (mecânica, narrativa, inteligência artificial etc.), a importância do tema está na interpretação do jogador - como a emergência é controlada, é necessário desenvolver ou focar em técnicas que garantam a incerteza sobre o sistema/gameplay. Com isto em mente, Costikyan (2013) afirma que jogos precisam ser incertos para serem interessante e existem várias fontes de incerteza para isto; ele enumera 11 fontes: incerteza performativa, incerteza da solução, imprevisibilidade do jogador, aleatoriedade, complexidade analítica, informação oculta, antecipação narrativa, antecipação de desenvolvimento, incerteza agendada, incerteza de percepção e incerteza semiótica.

Incerteza performativa (COSTIKYAN, 2013) envolve a performance física, a habilidade do jogador (player-skill) em executar as ações. Exigem atenção contínua e um excelente timing na utilização da interface de comando (joysticks, menus etc.); são bastante tensos. Para se criar desafio performativo, os desenvolvedores utilizam configurações de dificuldade variáveis ou dificuldade ajustada dinamicamente. Um bom exemplo são os jogos em FPS, que precisam de rapidez e uma boa mira dos jogadores.

A adaptação da dificuldade é um tema importante no design de jogos e merece um pouco mais de atenção. Primeiramente, ela não é exclusiva de jogos centrados na incerteza performativa. Diversos jogos utilizam a adaptabilidade para controlar o nível de incerteza com base tanto na dificuldade quanto na narrativa ${ }^{23}$. A adaptabilidade pode ser offline ou online (BIDARRA; LOPES, 2011). Offline refere-se às opções de configuração anterior ao início da partida; normalmente, nos menus, o jogador pode escolher o nível de dificuldade (fácil, normal, difícil), além de outras variáveis que impactarão direta ou indiretamente no gameplay (escolha de habilidades, magias, clãs e até o brilho da tela). Adaptabilidade online é dinâmica, pois ocorre após o jogo propriamente dito começar; pode ser de dois tipos: voluntária ou involuntária. A voluntária aparece como uma sugestão pelo sistema; como em God of War 3 (SANTA MONICA STUDIO, 2010), que após seguidas mortes do personagem, o próprio jogo "sugere" a alteração do nível de dificuldade para facilitar a execução da tarefa. A involuntária ajusta a dificuldade com base na performance: um jogador considerado fraco pelo sistema terá facilidades para progredir; em Mario Kart 64, a IA do jogo utiliza uma técnica conhecida como "rubber band", que ajusta a velocidade dos NPCs e a probabilidade dos itens para ajudar ou atrapalhar o jogador de acordo com sua posição na corrida (BIDARRA; LOPES, 2011).

Hunicke (2005) afirma que o Dynamic Difficulty Adjustement (DDA), ou Ajuste Dinâmico de Dificuldade, oferece uma alternativa de modular o sistema do jogo para responder às habilidades particulares dos jogadores. A adaptação dinâmica leva em consideração os dados do jogador, prévios (modelagem de personagens, dificuldade etc.) e coletados durante a partida (número de mortes, tempo de 
${ }^{24} \mathrm{Ou}$, como visto anteriormente neste trabalho, quando utilizado um modelo emergente de IA, mas que, pela necessidade de poder de processamento alto, é deixada de lado na versão final do jogo.

25 "the number of random tests in a system approaches infinity, outcomes regress to a mean, and there are so many random tests that player almost never see behavior that seems unusual" (COSTIKYAN, 2013: p. 42). execução, caminhos percorridos, itens utilizados etc.). Com isso, o desempenho é avaliado e uma política de ajuste é aplicada. Com os algoritmos certos, alega Hunicke, é possível ajustar tudo de um jogo, desde a estrutura narrativa ao layout físico dos mapas durante o jogo - a escolha do modelo de inteligência artificial é crucial na configuração adequada da adaptabilidade.

Retornando às fontes de incerteza enumeradas por Costikyan, a incerteza da solução (COSTIKYAN, 2013) é causada pelo desafio gerado por enigmas (puzzles). Em Curse of Monkey Island, o desafio é inteiramente mental e a incerteza está totalmente na capacidade de solução. O problema deste tipo de incerteza é o alto grau de artificialidade e arbitrariedade, pois o enigma e sua solução são totalmente definidos pelo sistema, o que impede que o jogador planeje soluções novas e criativas.

Imprevisibilidade do jogador (COSTIKYAN, 2013) é causada através da interação com outros agentes, humanos ou não. A interação com agentes não humanos é coordenada pela inteligência artificial. $O$ inconveniente é que humanos são inevitavelmente mais espertos e menos previsíveis, pois os códigos de IA são procedurais e previsíveis, exceto quando contém algum elemento aleatório ${ }^{24}$. Para resolver isto, os agentes aproveitam diferentes tipos de incerteza para prover a ilusão de imprevisibilidade aos jogadores.

Aleatoriedade (COSTIKYAN, 2013) ocorre quando o sistema "sorteia" um dado de maneira randômica. A princípio, baseia-se na sorte, entretanto, quando "o número de testes randômicos em um sistema se aproxima do infinito, os resultados regridem a uma média, e há tantos testes como estes que os jogadores nunca notam um comportamento que pareça incomum"25 (COSTIKYAN, 2013: p. 42, tradução nossa). Aleatoriedade pode ser usada como saída de programação para eventos que o jogador não possui controle direto ou não pode atribuir justificativa lógica, pois aumenta a verossimilhança. A quebra de um brinquedo no jogo RollerCoaster Tycoon (HASBRO INTERACTIVE, 1999) possui uma justificativa, mas esta não precisa ser programada (má utilização, tempo de uso, clima etc.), basta usar programas com evento aleatório. $\mathrm{O}$ jogador interpretará como evento possível, como faz na vida normal.

Complexidade analítica (COSTIKYAN, 2013) está nos jogos nos quais o jogador precisa raciocinar bem sobre o que fazer, analisar uma complicada árvore de decisão. Em geral, é o produto de um sistema que permite diversas opções, mas força uma escolha em detrimento das outras. O xadrez é um exemplo bem ilustrativo da incerteza por complexidade analítica: para vencer o jogo, é necessário um bom raciocínio sobre as opções estratégicas.

Informação oculta (COSTIKYAN, 2013), em muitos jogos, possui o papel principal de nutrir o desejo de exploração; muito do divertimento vem da descoberta de novos ambiente e personagens, desafios, objetos, eventos da história etc.

Antecipação narrativa (COSTIKYAN, 2013) é a incerteza no arco narrativo, é não saber o que virá a seguir, tanto sobre a história quanto qual evento ocorrerá. O sistema do jogo deve tentar garantir que sempre haja alguma tensão narrativa: incorporação constante de reforço negativo e garantir que qualquer jogador possa interferir no gameplay ou ser bem sucedido. Antecipar (especular) o que pode acontecer, mas não ter certeza é o que mantém o interesse do jogador em executar as ações, assim, o suspense possui um papel extremamente importante.

Antecipação de desenvolvimento (COSTIKYAN, 2013) é a incerteza sobre qual atualização o jogo sofrerá pelos seus desenvolvedores, é o desejo de ver como o jogo evoluirá em termos de recursos e ajustes.

Incerteza agendada (COSTIKYAN, 2013: 100-101) utiliza uma técnica chamada de "mecânica de reengajamento cronometrada"; seu propósito é induzir 
26 "The unpredictability of meaning that always accompanies attempts to interpret the game's outcomes" (MALABY apud COSTIKYAN, 2013: 102). jogadores a retornar ao jogo constantemente. Relaciona-se a jogos sociais, como CityVille e Candy Crush.

Incerteza de percepção (COSTIKYAN, 2013) foca na habilidade de percepção, na dificuldade em identificar o que está acontecendo no espaço do jogo. O clássico exemplo é o jogo de objetos escondidos. Em Gardens of Time, a incerteza está, primeiramente, na detecção dos itens espalhados na tela; depois, em lembrar onde estavam e continuar à frente do tempo-limite do relógio (COSTIKYAN, 2013).

E, por último, incerteza semiótica (COSTIKYAN, 2013) é, nas palavras de Malaby (apud COSTIKYAN, 2013: 102, tradução nossa) "a imprevisibilidade de significado que sempre acompanha tentativas de interpretar o resultado de um jogo"26 - ou seja, é o julgamento de significado que um jogo representa. A princípio, poder-seia afirmar que por ser externa à estrutura formal do jogo, não seria relevante para a exploração de incerteza, mas, por outro lado, há jogos que deliberadamente trabalham para criar significado cultural. Como exemplo, há os newsgames que utilizam fatos atuais como tema dos jogos.

Costikyan (2013) aponta dois erros no desenvolvimento de jogos relacionados a incerteza: falta de incerteza e excesso de incerteza. Os dois podem gerar obviedade, frustração, alta ou baixa dificuldade e inexistência de surpresa, tensão ou suspense. O ideal, portanto, seria combinar diferentes fontes de incerteza, ou incluir uma nova fonte nos diferentes gêneros já consolidados (COSTIKYAN, 2013).

\section{Considerações Finais}

Em uma das opções oferecidas a Stanley, contrariando o narrador, o personagem cai em uma armadilha e morre esmagado. Uma voz feminina começa a falar sobre a relação entre os dois, enquanto Stanley cai em uma nova sala:

Olhe para estes dois. Como eles querem destruir um ao outro. Como eles desejam controlar o outro. Como eles desejam ser livres. Você pode ver? Você pode ver o quanto eles precisam um do outro? Não, talvez não. Às vezes, essas coisas não podem ser vistas... ${ }^{27}$

27 "Look at these two. How they wish to destroy one another. How they wish to control one another. How they both wish to be free. Can you see? Can you see how much they need one another? No, perhaps not. Sometimes these things cannot be seen..."

\footnotetext{
${ }^{28}$ Parte-se do pressuposto que jogos eletrônicos, de maneira geral, causam uma experiência positiva nos jogadores. Isto é facilmente averiguado, dentre outros fatores, através do crescimento constante da indústria ou do aumento do número de sites especializados, canais de gameplay no Youtube e seções dedicadas em grandes portais da internet.
}

O jogo brinca com a ideia de controle, com a disputa por liberdade tanto do sistema/ narrador quanto do personagem/jogador. Em determinados momentos, o narrador percebe que não pode prever tudo, então passa a "implorar" por obediência; em outros, o jogador se encontra em situações cuja única saída é fazer o que o narrador "pede". Ou seja, no fundo, eles são dependentes e cúmplices na experiência do jogo.

A Inteligência Artificial serve tanto para controlar e limitar o poder do processamento emergente quanto para gerar a sensação de imprevisibilidade através da incerteza sobre os eventos do jogo. Criar agentes inteligentes é criar autonomia e, portanto, comportamento independente. E independência é descontrole sobre as decisões dos outros e liberdade de escolha própria. Incerteza, então, é pseudoliberdade com sensação de liberdade total - fundamental para a imersão no mundo do jogo.

A constatação de que o jogo não é um sistema inteligente - pelo menos, se comparado ao ser humano e sua dinâmica social - e possui restrições diretas, através das regras, e indiretas, através da inteligência artificial, poderia levar o jogador a descartar a experiência do jogo. Mas não é isto o observado ${ }^{28}$. Sendo assim, é possível, e desejável, relacionar o estudo da emergência e incerteza nos jogos de videogame (controle autoral, regras restritivas, limitação da autonomia do sistema e do processamento etc.) com uma abordagem maior, caracterizada pela linguagem própria dos jogos de videogame. Saber jogar envolve reconhecer, ignorar e/ou aceitar a semântica particular do jogo eletrônico, envolve um tipo específico de letramento. 


\section{Referências bibliográficas}

AARSETH, Espen. Cybertext: perspective on ergodic literature. Baltimore: Johns Hopkins University Press; 1997.

AMARO, Fausto; MAIA, Alessandra; PERANI, Letícia. O Jogo das Máquinas: aproximações entre o xadrez e as pesquisas em inteligência artificial. In REGIS, Fátima; ORTIZ, Anderson; AFFONSO, Luis Carlos; TIMPONI, Raquel (Orgs.). Tecnologias de Comunicação e Cognição. Porto Alegre: Sulina, 2012

BIDARRA, R; LOPES, R. Adaptivity challenges in games and simulations: a survey. IEEE Transactions on Computational Intelligence and Al in Games. vol. 3, n. 2. Jun. 2011.

COSTIKYAN, Greg. Uncertainty in Games. Massachusetts: MIT Press, 2013

FRASCA, G. Ludology meets narratology: similitude and differences between (video)games and narrative. 1999. Disponível em: <www.ludology.org>. Acesso em: 23 mar. 2007.

JUUL, Jesper. The Game, the Player, the World: Looking for a Heart of Gameness. 2003. In: COPIER, M.; RAESSENS, J. Level Up: Digital Games Research Conference Proceedings. Utrecht: Utrecht University. Disponível em: <http://www.digra.org/ dl/db/05163.50560> Acesso em: 09 mar. 2012.

KARLSSON, Börje Felipe Fernandes. Um Middleware de Inteligência Artificial para Jogos Digitais. 2005. 126 f. Dissertação (Mestrado em INFORMÁTICA). Departamento de Informática, Pontifícia Universidade Católica, Rio de Janeiro.

KISHIMOTO, André. Inteligência Artificial em Jogos Eletrônicos. Disponível em: http://www.programadoresdejogos.com/trab_academicos/andre_kishimoto. pdf. Acesso em: 30/12/2013

HASBRO INTERACTIVE. RollerCoaster Tycoon. 1999.

HUIZINGA, Johan. Homo ludens: o jogo como elemento da cultura. São Paulo: Perspectiva, 2008.

HUNICKE, R. The case for dynamic difficulty adjustment in games. ACM SIGCHI International Conference On Advances In Computer Entertainment Technology. New York, 2005. p. 429-433

JOHNSON, Steven. Emergência: a vida integrada de formigas, cérebros, cidades e softwares. Rio de Janeiro: Jorge Zahar, 2003.

MAXIS. The Sims. 2000.

OLIVEIRA, Luis Alberto. Biontes, Bióides e Borgues. In: O Homem-Máquina: a ciência manipula o corpo. NOVAES, Adauto (org.). São Paulo: Companhia das Letras, 2003

REGIS, Fátima. Nós, Ciborgues: tecnologias de informação e subjetividade homemmáquina. Curitiba: Champagnat, 2012

ROCKSTAR NORTH. Grand Theft Auto V. 2013

ROCKSTAR NORTH. L.A. Noire. 2011.

RYAN, Marie-Laure. Narrative as virtual reality: immersion and Interactivity in Literature and Electronic Media. Baltimore; Londres: Johns Hopkins; 2001. 
. From narrative games to playable stories. StoryWorlds: A Journal of Narrative Studies, Nebraska, v. 1. 2009.

SALEN, Katie; ZIMMERMAN, Eric. Rules of play: game design fundamentals. Cambridge, MA: MIT Press; 2004

SANTA MONICA STUDIO. God of War 3. 2010

SCHWAB, Brian. Al Game Engine Programming. Massachusetts: Course Technology, 2009

SWEETSER, Penny. Emergence In Games. Massachusetts: Course Technology, 2008. 